УДК 347.1

С. П. Яковлева

Байкальский государственный университет, г. Иркутск, Российккая Федерация

\title{
ПРАВОВЫЕ ПОЗИЦИИ ЕВРОПЕЙСКОГО СУДА ПО ПРАВАМ ЧЕЛОВЕКА
}

\begin{abstract}
АНнотАция. Различные аспекты функционирования Европейского Суда по правам человека, система защиты прав человека изучаются и анализируются в России активно, значительная часть работ ограничивается вопросами процедуры обращения в наднациональную юрисдикцию и реализации индивидом права на международную защиту, либо исследованием воздействия на процессуальное право. Проблема квалификации правовых позиций представлена в новом ключе, с учетом последних позиций Конституционного Суда Российской Федерации в отношении решений Европейского Суда по правам человека. В статье рассматривается вопрос о влиянии правовых позиций на гражданское право. Кроме того последовательно доказывается возможность судебного правотворчества. Обобщаются имеющиеся подходы к пониманию природы правовой позиции суда. Показано, что Европейский Суд по правам человека, давая толкование некоторым положениям Конвенции о защите прав человека и основных свобод, ориентируется на ранее вынесенные собственные решения. Предлагается разграничение терминов «правовая позиция» и «решение Европейского Суда по правам человека» .

кЛЮЧЕВЫЕ СЛОВА. Гражданское право; международный договор; дееспособность; Европейский Суд по правам человека; правовые позиции; источник права; гражданские права и свободы; судебный прецедент.

ИНФОРМАЦИЯ О СТАТЬЕ. Дата поступления 8 июля 2016 г.; дата принятия к печати 16 августа 2016 г.; дата онлайн-размещения 30 сентября 2016 г.
\end{abstract}

S. P. Yakovleva

Baikal State University, Irkutsk, Russian Federation

\section{LEGAL POSITIONS OF THE EUROPEAN COURT OF HUMAN RIGHTS}

ABSTRACT. Various aspects of the European Court of Human Rights and the human rights protection system are actively investigated in the last decade in Russia. Numerous scientific papers are limited by the issues of treatment procedures to the supranational jurisdiction and implementation of the individual's right for international protection or investigation of impact on the procedural law. The problem of legal positions qualification is presented in a new way, taking into account the recent positions of the Constitutional Court of the Russian Federation in regard of the decisions of the European Court of Human Rights. The article considers an issue of legal positions impact on the civil law. Besides, it consistently proves a possibility of judicial legislation. It generalizes the existing approaches to understanding the nature of legal position of vessel. It shows that the European Court of Human Rights, by interpreting some positions of Convention for the Protection of Human Rights and Main Liberties, is guided by its own decisions adopted before. It offers to differentiate the terms «legal position» and «decision of the European Court of Human Rights» .

KEYWORDS. Civil Law; international treaty; capacity; legal competency; European Court of Human Rights; legal positons; legal competency; sources of law; civil rights and freedoms; judicial precedent.

ARTICLE INFO. Received July 8, 2016; accepted August 16, 2016; available online September 26, 2016.

Работа по модернизации институтов и отдельных норм гражданского права детерминирована в частности и процессами интеграции и взаимодействия национальной системы права и международно-правовых обязательств. Данный процесс

\section{Baikal Research Journal}


сложен в силу ряда причин. Так, Россия приняла демократический старт с запозданием, и новые принципы права (правосудия) накладываются на целый ряд традиций иного характера.

Тем не менее, войдя в Совет Европы, ратифицировав Конвенцию о правах человека от 1950 г. (далее - Конвенция), Российская Федерация заявила тем самым, что «іpso facto и без специального соглашения признает юрисдикцию Европейского Суда по правам человека обязательной по вопросам толкования и применения Конвенции ...»" ${ }^{1}$

Именно Европейский суд по правам человека (ЕСПЧ) можно расценить как гарант в обеспечении прав и свобод человека в случае нарушения гражданских, жилищных, имущественных прав. Россия взяла на себя обязательство приведения в соответствие с правовыми позициями ЕСПЧ национального законодательства (в том числе и гражданского) и правоприменительной практики.

Так, согласно ст. 7 Гражданского кодекса РФ (ГК РФ) общепризнанные принципы и нормы международного права, содержащиеся, в том числе и в международных договорах Российской Федерации, признаются частью правовой системы России. Ратифицированная Конвенция относится к числу международных договоров, однако вопрос касательно решений ЕСПЧ до сих пор не имеет однозначного ответа. Не получил и должной разработки вопрос о том, в какой степени общепризнанные принципы и нормы международного права отражены в решениях ЕСПЧ.

Отсутствие единого подхода к вопросам о природе правовых позиций ЕСПЧ, о степени обязательности их для российской стороны также является аргументом, говорящим об актуальности избранной темы. Разрешение данных проблем интересно еще и потому, что политическая напряженность привела к актуализации исполнений решений ЕСПЧ в России (имеется в виду об указании на юридическую силу решений ЕСПЧ в части их соотношения с нормами Конституции РФ и нормами конституционных законов $\left.{ }^{2}\right)$.

Кроме того, базисом германской частноправовой системы является то, что «основной формой выражения правовых норм является закон, а не правовой обычай или судебный прецедент» $[1$, с. 75]. В российской традиции сформировалось следующее доктринальное понимание относительно источника права в формальном (юридическом) смысле: это способы (формы) внешнего выражения и закрепления юридических норм, т. е. то, что фактически выступает в качестве внешних форм выражения позитивного права [2, с. 180]. Говоря о праве гражданском, верно следующее: при возникновении в праве пробела применяются общие начала и смысл гражданского законодательства, а также требования добросовестности, справедливости, разумности (ст. 6 ГК РФ).

Уяснить сущность юридической категории «правовая позиция» позволяет рассмотрение и анализ уже имеющихся философских и теоретических наработок, касающихся как позиций судов вообще, так и относящихся сугубо к деятельности ЕСПЧ.

М. Н. Марченко отмечает, что правовая позиция «совершенно новая, вошедшая в научный обиход только в начале 90-х гг. ХХ столетия, юридическая категория,

${ }^{1}$ О ратификации Конвенции о защите прав человека и основных свобод и Протоколов к ней : федер. закон РФ от 30 марта 1998 г. № 54-ФЗ // Собрание законодательства РФ. 1998. № 14. Ст. 1514.

${ }^{2}$ По делу о проверке конституционности положений статьи 1 Федерального закона «О ратификации Конвенции о защите прав человека и основных свобод и Протоколов к ней», пунктов 1 и 2 статьи 32 Федерального закона «О международных договорах Российской Федерации», частей первой и четвертой статьи 11, пункта 4 части четвертой статьи 392 Гражданского процессуального кодекса Российской Федерации, частей 1 и 4 статьи 13, пункта 4 части 3 статьи 311 Арбитражного процессуального кодекса Российской Федерации, частей 1 и 4 статьи 15, пункта 4 части 1 статьи 350 Кодекса административного судопроизводства Российской Федерации и пункта 2 части четвертой статьи 413 Уголовно-процессуального кодекса Российской Федерации в связи с запросом группы депутатов Государственной Думы : постановление Конституц. Суда РФ от 14 июля 2015 г. № 21-П // Российская газета. 2015. 27 июля.

\section{Baikal Research Journal}

электронный научный журнал Байкальского государственного университета 
неизменно ассоциируется лишь с конституционным правом, конституционной доктриной и, соответственно, с Конституционным Судом РФ» [3, с. 129]. Нельзя не согласиться, что более или менее данный вопрос разработан в лоне конституционного права и правосудия, в то время как положение в отраслевых юридических науках говорит о недостаточной разработанности рассматриваемой проблематики. Это справедливо и в отношении права гражданского. Далее отметим, что термин «позиция» имеет следующее определение - «положение, расположение; либо же точка зрения, мнение в каком-либо вопросе» [4, с. 707].

По мнению Е. С. Алисевич, правовые позиции представляют собой «обобщение практики толкования ЕСПЧ прав и свобод человека, гарантированных Конвенцией, которое становится правовой основной решений ЕСПЧ соответствующих ситуаций, связанных с применением этих прав» [5, с. 79]. В свою очередь Л. В. Власенко справедливо отмечает: «правовая позиция - это логико-языковой феномен, имеющий правовой характер, где высказывания и выводы являются его центром, содержательной основой» [6]. Таким образом, под правовыми позициями ЕСПЧ понимается результат толкования ЕСПЧ положений Конвенции, на основании которых ЕСПЧ разрешает дела. И правовые позиции применяются в дальнейшем при рассмотрении аналогичных дел.

Правовые позиции содержатся в мотивировочной части решения ЕСПЧ, являются результатом анализа аргументов и выводов, образующих правовое содержание судебного решения. ЕСПЧ может обращаться к собственным правовым позициям для аргументации позиций, т. е. следует правилу прецедента [7].

По мнению В. Д. Зорькина, Конституция РФ содержит механизм, посредством которого в отечественную правовую систему инкорпорирована Конвенция. Это означает следующее: решения ЕСПЧ в определенной степени содержат общепризнанные принципы и нормы международного права, именно поэтому они и являются частью отечественной правовой системы. Согласно ст. 15 Конституции РФ Конвенция введена в российскую правовую систему в качестве международного договора. Кроме всего Конвенция обладает приоритетом в отношении к федеральному закону. Одновременно в силу ст. 15 и 17 Конституции РФ Конвенция действует как инструмент признания, защиты прав, свобод гражданина и человека [8, с. 178].

Российским судам следует учитывать прецедентную практику ЕСПЧ. Этот вывод следует из того факта, что российская сторона официально признала юрисдикцию ЕСПЧ по вопросам применения и толкования Конвенции. Собственно Конституционный Суд РФ самолично ссылался на решения ЕСПЧ, тем самым оценивая его решения в качестве источника права. Таким образом, частью правовой системы России наряду с Конвенцией следует считать и решения ЕСПЧ.

В этой связи необходимо затронуть вопрос о проблемах исполнения решений ЕСПЧ в России, отбрасывающий к вопросу о национальном суверенитете, о сфере защиты прав человека. Отметим, что с 2015 г. в России создан механизм, позволяющий не исполнять решения ЕСПЧ. Согласно Постановлению Конституционного Суд РФ Россия может отступить от принятых на себя обязательств, если подобное отступление будет единственным способом избежать нарушения принципов и норм Конституции РФ. Поступив в духе собственных, ранее высказанных установок, которые также были социально и политически детерминированы, Конституционный Суд РФ встал на защиту интересов государства. Нельзя не упомянуть, что ЕСПЧ позволяет осуществить «выход на более высокую ступень толкования не только права, но и обстоятельств судебного дела с учетом естественных прав человека, международной практики...» $[9$, с. 22$]$.

Отметим, что согласно ст. 26 «Рacta sunt servanda» Венской Конвенции о праве международных договоров действует фундаментальный принцип международного

\section{Baikal Research Journal}

электронный научный журнал Байкальского государственного университета 
права: «каждый действующий договор обязателен для участников и по этой причине должен добросовестно выполняться» ${ }^{3}$. Ратифицировав Венскую Конвенцию о праве международных договоров, Россия обязана ее добросовестно выполнять: «сторона не может ссылаться на положения своего внутреннего права в качестве оправдания для невыполнения договора» (ст. 27). Вопрос о том, насколько нововведение будет препятствовать или способствовать в разрешении проблем защиты прав человека, покажет время. Хотя стоит отметить, что и Конституция РФ, и Конвенция защищает одни и те же права. Однако не всегда решения ЕСПЧ «удобны» для российской стороны (дело Константина Маркина ${ }^{4}$ ). В любом случае этот шаг - некая полумера, поскольку речи о выходе из Совета Европы, который предполагает денонсацию Конвенции, пока не стоит. Полагаем, что Россия, как и другие европейские государства, должна бороться за сохранение своего суверенитета, так и за бережное отношение к Конвенции, защиту ее от неадекватных и сомнительных решений. В любом случае необходимо учитывать особенности различных правовых культур, разрабатывая единые наднациональные стандарты в области защиты прав человека. Этот процесс подразумевает в обязательном порядке и взаимные уступки.

Исходя из обязательности исполнения решений ЕСПЧ (в случае их соответствия Конституции РФ) и следованию его правовым позициям, разрешим вопрос о том, какие из решений ЕСПЧ следует считать прецедентными. Так, Л. М. Энтин утверждает, что «лишь особо значимые судебные решения приобретают прецедентный характер. Формально обязательное лишь для спорящих сторон такое решение на деле становится самостоятельным источником права» [10, с. 113]. Однако представляется довольно трудным выработать критерии, по которым можно выделить эти «особо значимые» решения.

Как отмечают В. А. Туманов и Л. М. Энтин, решения, относящиеся к первым двум десятилетиям деятельности ЕСПЧ, как правило, больше по объему, чем решения последних лет, и их мотивировочная часть более обстоятельная, детальная. По большому счету этот вопрос остается открытым.

Некоторые авторы высказывают мнение, что появился новый источник права международный судебный прецедент. Так, А. В. Деменева отмечает, что «Постановление Пленума Верховного Суда РФ “О применении судами общей юрисдикции общепризнанных норм и принципов международного права и международных договоров Российской Федерации", в котором отмечается, что в силу п. 1 ст. 46 Конвенции решения ЕСПЧ, принятые окончательно, являются обязательными для всех органов государственной власти Российской Федерации, в том числе и для судов фактическое признание того, что в сфере регулирования отношений внутри государства появился новый источник права: международный судебный прецедент» $[11$, с. 28]. Далее автор меняет точку зрения, полагая, что решения ЕСПЧ нельзя считать прецедентами [12, с. 13].

Фактически решения ЕСПЧ - это нормы Конвенции в их динамике и развитии. Сам ЕСПЧ не раз выражал свою позицию в формулировке: «Конвенция - живой инструмент и должна толковаться в свете сегодняшнего дня». Данный вид толкования в юридической литературе получил название динамико-эволютивного [13, с. 113]. Полагаем, что для государства обязательны решения, вынесенные не только в отношении дела, где оно является участником, но и в отношении иных стран-участниц Совета Европы.

${ }^{3}$ Венская Конвенция о праве международных договоров : заключена в Вене 23 мая 1969 г. // Ведомости ВС СССР. 1986. № 37. Ст. 772.

4 Дело «Константин Маркин (Konstantin Markin) против Российской Федерации» (жалоба № 30078/06) : постановление ЕСПЧ от 22 марта 2012 г. // Бюллетень Европейского Суда по правам человека. 2012. № 6. С. 3, 62-105.

\section{Baikal Research Journal}

электронный научный журнал Байкальского государственного университета 
Анализируя решения ЕСПЧ как акт толкования права, можно выделить следующие их признаки: содержат в себе общие правила поведения их разъяснения, поэтому решения ЕСПЧ являются актами авторитетного судебного органа, а не только нормативными правилами; адресуются, как правило, участникам процесса и носят обязательный характер. Однако в отличие от акта толкования решения ЕСПЧ содержат и нормативные предписания, имеют самостоятельное значение и, что самое главное, включают решение по делу.

Кроме того, акты толкования не являются формой и источником права. П. В. Волосюк считает, что «ЕСПЧ в процессе принятия решения по конкретному делу создает норму толкования» $[14$, с. $66-67]$. При этом, обозначая признаки этой нормы, автор фактически перечисляет признаки, присущие правовым позициям (ratio decidendi) ЕСПЧ.

Содержащиеся в окончательном решении по делу ссылки на правовые позиции, выработанные и применявшиеся ЕСПЧ в более ранних решениях; новые нормы, которые конкретизируют Конвенцию, дают возможность рассуждать о степени их обязательности. Государство способно предпринять шаги в законодательной, правоприменительной сфере (для соблюдения международного договора - Конвенции) именно благодаря заключенным в решении ЕСПЧ правовым позициям.

В юридической литературе высказывается также мнение о том, что решения ЕСПЧ являются правоприменительными актами, и, следовательно, их нельзя считать частью российской правовой системы $[15$, с. 238]. Однако в отличие от правоприменительного акта, решение ЕСПЧ имеет силу не только для строго определенных ситуаций и лиц, но и распространяется на аналогичные случаи в будущем. И главное, оно рассчитано на многократное применение. Для подтверждения данной точки зрения стоит обратиться к делу «Претти против Соединенного Королевства» ${ }^{5}$. ЕСПЧ утверждал о прецедентном характере решений по конкретным делам в большей или меньшей степени. Собственно и само решение «Претти против Соединенного Королевства» ЕСПЧ выносил и расценивал таким образом, что «ни с практической, ни с теоретической точки зрения не видел препятствий, чтобы не допустить его применения в будущих делах». Адвокат же заявительницы убеждал ЕСПЧ, что нарушение Конвенции не создает прецедента в настоящем деле.

Как отмечает М. Энтин: «В силу сформировавшегося в Европе международно-правового обычая и эволюции конституционных традиций решения ЕСПЧ рассматриваются государствами-участниками Совета Европы и их судебными органами как имеющее прецедентное значение, как общий стандарт, следование которому является юридически обязательным» $[16$, с. 85$]$.

Полагаем, что эволютивное толкование норм, содержащихся в Конвенции, есть отражение современного развития европейского общества, тенденции правового регулирования в странах-участницах Совета Европы.

Анализ позволяет сделать следующее обобщение: фактически каждое решение ЕСПЧ содержит в себе толкование норм Конвенции и протоколов к ней, т. е. дает ее нормативное толкование. Кроме того, решения ЕСПЧ являются прецедентом толкования, правоприменительным актом.

Природа решений ЕСПЧ триедина, включает в себя признаки акта толкования, правоприменительного акта, прецедента толкования. Центром, ядром в данном понимании является прецедентный характер решения ЕСПЧ. И наличие правовых позиций в структуре решений ЕСПЧ и наделяет его признаком, свойственным прецедентному решению.

${ }^{5}$ Дело «Претти (Pretty) против Соединенного Королевства» (жалоба № 5129 / 03) : постановление ЕСПЧ от 29 апр. 2002 г. // Прецеденты Европейского Суда по правам человека по странам-членам Совета Европы. 2007. № 10. С. 26.

\section{Baikal Research Journal}

электронный научный журнал Байкальского государственного университета 
Иными словами, применяя и толкуя Конвенцию в рамках конкретного дела, по конкретным обстоятельствам ЕСПЧ создает новые правовые позиции. Решения ЕСПЧ можно воспринимать как акты, содержащие в себе определенные нормы права (правила, правовые позиции), которые следует применять при рассмотрении аналогичных дел субъектам права: странам - участникам Совета Европы.

Для российских судов обязательной к применению является не все решение, а та его часть, в которой излагаются правовые позиции ЕСПЧ. Следовательно, на мотивировочную часть решения ЕСПЧ необходимо опираться при рассмотрении дела. Однако не совсем корректно рассматривать правовые позиции ЕСПЧ в качестве источника права, его внешнего выражения, поскольку позиции есть норма права, а решение ЕСПЧ признается источником права.

В этом ключе интересна демонстрация пути в вопросе о признании судебного правотворчества в европейском и американском праве. Так, А. Г. Карапетов высказывает мнение о «невозможности избежать судебного правотворчества как при осуществлении пробельного правотворчества, так и при толковании норм закона. Судебное правотворчество есть, так как его попросту невозможно избежать» $[17$, c. 304$]$. Ученый также отмечает, что « тенденция в полной мере соответствует общеевропейской линии вовлечения судов в активное правотворчество. Здесь мы имеем в виду крайне активное правотворчество ЕСПЧ, а также Европейского суда справедливости, которые давно присвоили себе компетенцию создавать правовые нормы на основе интерпретации крайне абстрактных принципов Конвенции и основополагающих нормативных договоров, лежащих в основе Европейского союза соответственно» $[17$, с. 172$]$.

Действительно, правовые позиции ЕСПЧ и Европейского суда справедливости можно отнести к «правотворческим инновациям», которые являлись одним из главных локомотивом европейской интеграции. Толкуя основополагающие документы, давая им «проинтеграционные» интерпретации, европейские судебные органы совершают то, о чем страны-участницы Европейского Союза и Совета Европы не предполагали, заключая международные договора. Неудивительно, что во многих странах континентальной Европы, где главенствующее положение в качестве источника права занимает нормативно-правовой акт, решения ЕСПЧ являются судебными актами, которые официально признаются источником национального права, например, в Украине 6 .

Полагаем, что в сфере защиты прав и свобод человека правовые позиции ЕСПЧ влияют на нормотворческую деятельность национальных органов государств-участниц Совета Европы, поскольку после выявления противоречия между национальными правовыми актами и правовыми позициями ЕСПЧ государство обязано согласно международному договору привести в соответствие собственное законодательство с нормами права Совета Европы и решениями ЕСПЧ.

Отметим, что при отсутствии конкуренции между правовыми позициями Конституционного Суда РФ и ЕСПЧ отчетливо прослеживается механизм влияния правовых позиций ЕСПЧ, например, на гражданское право. Так, вынесенное в 2008 г. решение ЕСПЧ по делу «Штукатуров против России» ${ }^{7}$ стало первым делом, в котором ЕСПЧ подверг обстоятельному анализу и серьезной критике процедурные и содержательные аспекты института недееспособности в России. Последствия, которые влечет для лица установление ему такого статуса, также получили отрицатель-

${ }^{6}$ Об исполнении решений и применении практики Европейского суда по правам человека : закон Украины от 23 февр. 2006 г. № 3477-IV // Ведомости Верховной Рады Украины. 2006. № 30. Ст. 260.

7 Дело «Штукатуров (Shtukaturov) против Российской Федерации» (жалоба № 44009 / 05) : постановление ЕСПЧ от 27 марта 2008 г. // Российская газета. 2009. № 2. С. 100.

\section{Baikal Research Journal}

электронный научный журнал Байкальского государственного университета 
ную оценку. Ссылаясь на выводы ЕСПЧ по делу Штукатурова Суд РФ признал взаимосвязанные положения п. 1 и 2 ст. 29, п. 2 ст. 31 и ст. 32 ГК РФ не соответствующими Конституции Р $\Phi^{9}$.

При этом Конституционный Суд РФ указал, что федеральному законодателю необходимо трансформировать существовавший механизм защиты прав граждан, которые страдают психическими расстройствами. Данные изменения позволяли бы суду учитывать степень нарушения способности граждан понимать значение собственных действий, руководить ими. Во исполнение данного Постановления Федеральным законом от 30 декабря 2012 г. были внесены изменения в ГК РФ, вводящие дифференцированный статус дееспособности для лиц с психическим расстройством. Был принят Федеральный закон ${ }^{10}$, предусматривающий категорию граждан, признаваемых частично дееспособными в гражданском законодательстве.

Какой бы смысл отечественная наука не вкладывала в понимание судебного прецедента, в любом случае его основу составляет правовая позиция (в нашем случае правовая позиция ЕСПЧ). Самостоятельно выработанная ЕСПЧ новая правовая позиция есть нормотворческая составляющая решения, которое и является источником права для любого государства-участника Совета Европы. Приведенный вывод указывает и на демаркацию понятий «правовая позиция» и «решение суда», которые не следует отождествлять.

В качестве основного вывода уточним, что решения ЕСПЧ имеют нормотворческую составляющую, которая заключена в правовых позициях ЕСПЧ. Под правовыми позициями ЕСПЧ понимаются правила поведения, вырабатываемые данным судом посредством конкретизации норм, содержащихся в Конвенции и применяемые в дальнейшем при разрешении аналогичных дел. В то же время рассмотрение отечественного гражданского законодательства сквозь призму правовых позиций ЕСПЧ позволяет обнаружить возможность совершенствования отечественного частного права.

Важно, что правовые позиции ЕСПЧ, отраженные в решениях, позволяют спрогнозировать дальнейшее поступательное движение и эволюционное развитие гражданского законодательства и права с учетом общеевропейских тенденций. В этом отношении дается некая "привилегия" государствам-участницам Конвенции, поскольку можно употребить для национальных правовых нужд наработки ЕСПЧ, которые уже аккумулируют в себе опыт, прогрессивные правовые наработки в области защиты прав лиц. На наш взгляд, для российского государства поэтому важно сохранять членство в Совете Европы и, как следствие, юрисдикцию ЕСПЧ. Возможно, что отечественному законодателю следует быть более прогрессивным, ведь степень его развития в сфере гражданского права должна соответствовать международным стандартам, а это становится возможным благодаря применению системного подхода в регулировании и совершенствовании российской правовой системы в целом.

Безусловно, что следование позициям ЕСПЧ без отсылки на религиозные, исторические, культурные, цивилизационные особенности конкретных народов может умалить национальную самобытность. Разрешение подобной проблемы видится в том, чтобы дифференцировать ситуации и случаи, в которых оппозиция исполне-

\footnotetext{
${ }^{8}$ Постановление ЕСПЧ от 27 марта 2008 г. С. 98.

${ }^{9}$ По делу о проверке конституционности ряда положений статей $37,52,135,222,284,286$ и 379.1 Гражданского процессуального кодекса Российской Федерации и части четвертой статьи 28 Закона Российской Федерации «О психиатрической помощи и гарантиях прав граждан при ее оказании» в связи с жалобами граждан Ю. К. Гудковой, П. В. Штукатурова и М. А. Яшиной : постановление Конституц. Суда РФ от 27 февр. 2009 г. № 4-П // Собрание законодательства РФ. 2009. № 11. Ст. 1367.

${ }^{10} \mathrm{O}$ внесении изменений в главы $1,2,3$ и 4 части первой Гражданского кодекса Российской Федерации : федер. закон РФ от 30 дек. 2012 г. № 302-Ф3 // Собрание законодательства РФ. 2012. № 53, ч. 1. Ст. 7627.
}

\section{Baikal Research Journal}


ния решения ЕСПЧ против России на самом деле вызвана неприемлемостью решения для отечественной правовой системы и общества в целом от случаев, когда во многом устаревший и косный государственный принцип безосновательно сопротивляется прогрессу (как в деле Маркина против России ${ }^{11}$ ).

\section{Список использованной литературы}

1. Райников А. С. Основные частноправовые семьи: общие черты / А. С. Райников // Журнал российского права. - 2013. - № 9. - С. 72-80.

2. Пьянов Н. А. Консультации по теории государства и права : учеб. пособие / Н. А Пьянов. - Иркутск : Изд-во Иркут. гос. ун-та, 2010. - 583 с.

3. Марченко М. Н. Судебное правотворчество и судейское право / М. Н. Марченко. — М. : Проспект, 2007. - 512 с.

4. Ожегов С. И. Словарь русского языка : ок. 53000 слов / С. И. Ожегов, Л. И. Скворцов. - 24-е изд. - М. : Мир и образование, 2007. - 1200 с.

5. Алисевич Е. С. Толкование норм конвенции Совета Европы о защите прав человека и основных свобод как правомочие Европейского Суда по правам человека : дис. ... канд. юрид. наук : 12.00.01 / Е.С. Алисевич. - М., 2006. - 147 с.

6. Власенко Л. В. Налоговые правовые позиции судов: теория и практика : монография / Л. В. Власенко. - М. : Норма, 2011. - 160 с.

7. Караманукян Д. Т. Акты Европейского суда по правам человека в российской правовой системе : учеб. пособие / Д. Т. Караманукян. - Омск : Омская юрид. акад., 2013. - 96 с.

8. Зорькин В. Д. Роль Конституционного Суда Российской Федерации в реализации Конвенции о защите прав человека и основных свобод / В. Д. Зорькин // Имплементация решений Европейского Суда по правам человека в практике конституционных судов стран Европы : сб. докл. - М. : Ин-т права и публичной политики, 2006. - С. 173-182.

9. Амосов С. М. Истина и смысл правосудия / С. М. Амосов // Российское правосудие. 2013. - № 5 (85). - С. 21-26.

10. Европейское право. Право Европейского Союза и правовое обеспечение защиты прав человека : учебник / М. В. Каргалова, Е. Ю. Козлов, С. О. Корогод [и др.] ; отв. ред. Л. М. Энтин. - 2-е изд., перераб. и доп. - М. : Норма, 2005. - 960 с.

11. Деменева А. В. Юридические последствия постановлений Европейского Суда по правам человека для Российской Федерации : дис. ... магистра права : 521409 / А. В. Деменева. - Екатеринбург, 2004. - 103 с.

12. Деменева А. В. Юридические последствия постановлений Европейского Суда по правам человека для Российской Федерации : автореф. дис. ... канд. юрид. наук : 12.00.10 / А. В. Деменева. - Казань, 2009. - 26 с.

13. Алкема Е. А. Юридические последствия ратификации Российской Федерацией европейской Конвенции о защите прав и основных свобод человека (включая 11-й протокол) / Е. А. Алкема // Российский ежегодник международного права. 1995. - СПб. : Россия-Нева, 1996. - С. 110-131.

14. Волосюк П. В. Решения Европейского Суда по правам человека как источник уголовного права России : дис. ... канд. юрид. наук : 12.00.08 / П. В. Волосюк. - Ставрополь, 2005. $-172 \mathrm{c}$.

15. Витрук Н. В. О юридической силе решений Европейского Суда но правам человека / Н. В. Витрук // Общепризнанные принципы и нормы международного права, международные договоры в практике конституционного правосудия : материалы Всерос. совещания. Москва, 24 дек. 2002 г. / под ред. В. К. Бобровой, С. В. Кабышева М. А. Митюкова, А. В. Сычевой. - М. : Междунар. отношения, 2004. - С. 237-243.

16. Энтин М. Л. Справедливое судебное разбирательство по праву Совета Европы и Европейского Союза / М. Л. Энтин // Конституционное право: восточноевропейское обозрение. 2003. - № 3. - C. 85-97.

17. Карапетов А. Г. Борьба за признание судебного правотворчества в европейском и американском праве : монография / А. Г. Карапетов. - М. : Статут, 2011. - 308 с.

\footnotetext{
${ }^{11}$ Постановление ЕСПЧ от 22 марта 2012 г.
}

\section{Baikal Research Journal}




\section{References}

1. Rainikov A. S. Basic systems of private law: common features. Zhurnal rossiyskogo pra$v a=$ Journal of Russian Law, 2013, no. 9, pp. 72-80. (In Russian).

2. Pyanov N. A. Konsul'tatsii po teorii gosudarstva i prava [Advice on Theory of State and Law]. Irkutsk State University Publ., 2010. 583 p.

3. Marchenko M. N. Sudebnoe pravotvorchestvo i sudeiskoe pravo [Court law-making and judicial law]. Moscow, Prospekt Publ., 2007. 512 p.

4. Ozhegov S. I., Skvortsov L. I. (ed.). Slovar' russkogo yazyka [Dictionary of the Russian Language] $24^{\text {th }}$ ed. Moscow, Mir i Obrazovanie Publ., 2007. $1200 \mathrm{p}$.

5. Alisevich E. S. Tolkovanie norm konventsii Soveta Evropy o zashchite prav cheloveka $i$ osnovnykh svobod kak pravomochie Evropeiskogo Suda po pravam cheloveka. Kand. Diss. [Interpretation of norms of the Convention of European Union on protection of human rights and basic liberties as legal power of the European Court of Human Rights. Cand. Diss.]. Moscow, 2006. $147 \mathrm{p}$.

6. Vlasenko L. V. Nalogovye pravovye pozitsii sudov: teoriya i praktika [Tax legal positions of courts: theory and practice]. Moscow, Norma Publ., 2011. 160 p.

7. Karamanukyan D. T. Akty Evropeiskogo suda po pravam cheloveka $v$ rossiiskoi pravovoi sisteme [Acts of the European Court of Human Rights in Russian legal system]. Omsk Law Academy Publ., 2013. 96 p.

8. Zor'kin V. D. Role of the Constitutional Court of the Russian Federation in implementing the Convention for the Protection of Human Rights and Basic liberties. Implementatsiya reshenii Evropeiskogo Suda po pravam cheloveka $v$ praktike konstitutsionnykh sudov stran Evropy [Implementing decisions of the European Court of Human Rights in practice of constitutional courts of European countries] Moscow, Institute of Law and Public Policy Publ., 2006, pp. 173-182. (In Russian).

9. Amosov S. M. Truth and meaning of justice. Rossiiskoe pravosudie $=$ Russian Justice, 2013, no. 5 (85), pp. 21-26. (In Russian).

10. Kargalova M. V, Kozlov E. Yu., Korogod S. O. et al.; Entin L. M. (ed.). Evropeiskoe pravo. Pravo Evropeiskogo Soyuza i pravovoe obespechenie zashchity prav cheloveka [European Law. Law of European Union and legal provision of human right protection]. $2^{\text {nd }}$ ed. Moscow, Norma Publ., 2005. $960 \mathrm{p}$.

11. Demeneva A. V. Yuridicheskie posledstviya postanovlenii Evropeiskogo Suda po pravam cheloveka dlya Rossiiskoi Federatsii. Magistr. Dis. [Juridical consequences of decisions of the European Court of Human Rights for the Russian Federation] Master Degree Diss.]. Yekaterinburg, $2004.103 \mathrm{p}$

12. Demeneva A. V. Yuridicheskie posledstviya postanovlenii Evropeiskogo Suda po pravam cheloveka dlya Rossiiskoi Federatsii. Avtoref. Kand. Diss. [Juridical consequences of decisions of the European Court of Human Rights for the Russian Federation. Cand. Diss. Thesis]. Kazan, 2009. $26 \mathrm{p}$.

13. Alkema E. A. Juridical consequences of ratifying the European Convention for the Protection of Human Rights and Basic Liberties by the Russian Federation (including the 11-th Protocol). Rossiiskii ezhegodnik mezhdunarodnogo prava. 1995 [Russian Yearbook of International Law. 1995]. Saint Petersburg, Rossiya-Neva Publ., 1996, pp. 110-131. (In Russian).

14. Volosyuk P. V. Resheniya Evropeiskogo Suda po pravam cheloveka kak istochnik ugolovnogo prava Rossii. Kand. Diss. [Decisions of the European Court of Human Rights as a source of Russia's Criminal Law. Cand. Diss.]. Stavropol', 2005. 172 p.

15. Vitruk N. V. On juridical strength of decisions of the European Court of Human Rights. In Bobrova V. K. Kabyshev S. V., Mityukov M. A., Sycheva A. V. (eds). Obshchepriznannye printsipy i normy mezhdunarodnogo prava, mezhdunarodnye dogovory $v$ praktike konstitutsionnogo pravosudiya. Materialy Vserossiiskogo soveshchaniya. Moskva, 24 dek. 2002 g. [Generally recognized principles and norms of the international law, international treaties in practice of constitutional jurisdiction. Materials of All-Russia Conference, Moscow, December 24, 2002]. Moscow, Mezhdunarodnye otnosheniya Publ., 2004, pp. 237-243. (In Russian).

16. Entin M. L. Justified court examination according to the rights of European Counsel and European Union. Konstitutsionnoe parvo: vostochnoevropeiskoe obozrenie = Constitutional Law: Eastern European Review, 2003, no. 3, pp. 85-97. (In Russian).

\section{Baikal Research Journal}


17. Karapetov A. G. Bor'ba za priznanie sudebnogo pravotvorchestva $v$ evropeiskom $i$ amerikanskom prave [Fight for acknowledgement of judicial legislation in European and American laws]. Moscow, Statut Publ., 2011. 308 p.

\section{Информация об авторе}

Яковлева Софья Петровна - аспирант, кафедра гражданского права и процесса, Байкальский государственный университет, 664003, г. Иркутск, ул. Ленина, 11, e-mail: sofya.yakovleva-2016@mail.ru.

\section{Author}

Sofya P. Yakovleva - PhD Student, Chair of Civil Law and Procedure, Baikal State University, 11 Lenin St., 664003, Irkutsk, Russian Federation; e-mail: sofya.yakovleva-2016@mail.ru.

\section{Библиографическое описание статьи}

Яковлева С. П. Правовые позиции Европейского Суда по правам человека / С. П. Яковлева / / Baikal Research Journal. — 2016. — T. 7, № 5. — DOI : 10.17150/2411-6262.2016.7(5).23.

\section{Reference to article}

Yakovleva S. P. Legal positions of the European Court of Human Rights. Baikal Research Journal, 2016, vol. 7, no. 5. DOI : 10.17150/2411-6262.2016.7(5).23. (In Russian).

\section{Baikal Research Journal}

